\title{
Contribution of the Compass satellite navigation system to global PNT users
}

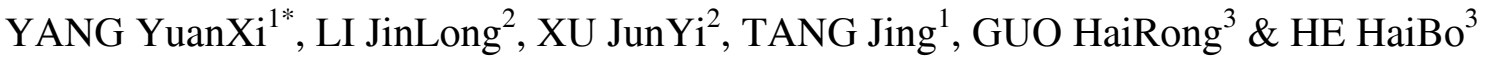 \\ ${ }^{1}$ China National Administration of GNSS and Applications, Beijing 100088, China; \\ ${ }^{2}$ Institute of Surveying and Mapping, Information Engineering University, Zhengzhou 450052, China; \\ ${ }^{3}$ Beijing Global Information Center of Application and Exploitation, Beijing 100094, China
}

Received April 6, 2011; accepted June 3, 2011

\begin{abstract}
As one of the four global satellite navigation systems, Compass not only enhances satellite visibility and availability for positioning, navigation and timing (PNT) for users in China and the surrounding areas, but also improves PNT precision for global users. The improvements in satellite visibility and the dilution of precision are analyzed under GNSS compatibility and interoperation conditions. The contribution of the Compass satellite navigation system to global users, especially the benefits that users can acquire from the combination of Compass, GPS, GLONASS, and Galileo navigation systems, is analyzed using simulation data.
\end{abstract}

Compass satellite navigation system, positioning, navigation, timing, DOP, satellite visibility

Citation: Yang Y X, Li J L, Xu J Y, et al. Contribution of the Compass satellite navigation system to global PNT users. Chinese Sci Bull, 2011, 56: 2813-2819, doi: $10.1007 / \mathrm{s} 11434-011-4627-4$

Global navigation satellite system (GNSS) is in blossom now. The sky has been shined with the Global Positioning System (GPS) of the United States, the Global Navigation Satellite System (GLONASS, whose full name is interestingly the same as that of GNSS) of Russia, the Galileo satellite navigation system (Galileo) of Europe, the Quasi-Zenith Satellite System (QZSS) of Japan, The Indian Regional Navigational Satellite System (IRNSS) and the navigation system of China (known as Beidou-2 or Compass). The frequencies available for satellite navigation users have thus been enriched. There will be 30 GPS satellites (with 3 frequencies), 24 GLONASS satellites (with 3 frequencies), 30 Galileo satellites (with 4 frequencies), 35 Compass satellites (with 3 frequencies), 3 QZSS satellites (with 4 frequencies) and 7 IRNSS satellites (with 2 frequencies) in outer space by 2020 [1-3]. World-wide users will be able to take advantage of multi-frequency observations from multi-constellations for positioning, navigating and timing (PNT) services. This will reduce the dependency on a single

*Corresponding author (email: yuanxi_yang@163.com) constellation and reduce the possibility of service interruption or performance degradation caused by electromagnetic interference, terrain or building sheltering, ionospheric scintillation, denial of service and so on.

The number of satellite and range signals will increase significantly and the navigation performance index will be greatly augmented by data detecting, sifting, and combination under the environment of GNSS multi-constellation and multi-frequency data fusion. All in all, the main advantages can be summarized as [4]: (1) The number of visible satellites will be increased, the dilution of precision (DOP) will be decreased, and the navigation accuracy will be enhanced. (2) Every individual navigation system has its own time, coordinate and orbit system errors. The influence of system errors in a single navigation system can be compensated for, and the precision of the orbit, satellite clock and the coordinates of the monitoring station of each individual system can be further improved by multiconstellation data fusion. The reliability of the satellite navigation system and the user PNT will thus be enhanced. (3) The synthetic use of multi-constellation and multi-fre- 
frequency signals can reduce hidden risks such as inadequate satellite numbers, major failures or service rejection, so the navigation availability will be improved; (4) Because of satellite observation redundancy, it is more convenient to diagnose, warn of, and segregate any significant fault, enhancing the integrity for navigation users. (5) Multiconstellations will improve the geometric strength, and this will be useful for diagnosing abnormal observations triggered by ionospheric scintillation, multipath and sheltering, thus ameliorating the user system's ability to control abnormal errors, and so enhance the robustness of the user's PNT. (6) The increase of satellite number will largely reduce the navigational blind areas, and relieve the navigation signal shortage problems caused by satellite failure, terrain/building/tree shadowing and other factors present in a single constellation situation; thus enhancing the continuity of the navigation system. (7) The influence of colored noise (varies with time) of satellite signals in a single constellation, improves the PNT convergence for dynamic users. (8) The use of multi-frequency signals can eliminate or enable the precise estimate of the ionospheric delay. (9) The instantaneous fixing of integer ambiguity will be possible with the synthetic use of multi-constellation and multifrequency signals. Even in long range terms, the integer ambiguity can be fixed reliably, which will then improve the time resolution of the estimates of troposphere delay parameters, and eventually improve the ability of high precision real-time and near real-time measurements. (10) The estimates of the accuracy of earth orientation parameters can be improved because of the different orbital altitude and orbit inclination of satellites in different navigation systems.

To analyze the contribution of Compass to user's PNT, we need to describe the influence of the stochastic error and system error under the condition of multi-navigationsystems. The dilution of precision (DOP) is the significant index for evaluating the compensation ability of stochastic and system errors, availability, and integrity. DOP describes the propagation of random error (noise) in measurements into the noise levels of the unknown (solved for) parameters [5]. Position error is the product of errors in measurement of horizontal DOP (HDOP) and vertical DOP (VDOP) [6].

The contribution of Compass is analyzed by simulated calculations. Similar research has been undertaken and has yielded many useful results [7-10]. This paper focuses first on the improvements to satellite visibility and second on the theory of the DOP value brought by Compass. The amelioration of satellite visibility and the DOP for global users is analyzed using simulated data.

\section{The contribution of increasing the constellation to the DOP}

The dilution of precision (DOP) is generally used to analyze the precision of navigation and geometric strength of observations. For the definition of DOP, there are many reference documents $[5,6,11]$ available. Supposing that the pseudo-range measurement is $P_{i}$, then the observation model can be written as

$$
P_{i}=\rho_{i}+c\left(\mathrm{~d} t_{u}-\mathrm{d} t_{i}\right)+I_{i}+T_{i}+e_{i},
$$

where $\rho_{i}$ refers to the geometric range between the antenna phase center of the receiver at the signal receive time and the antenna phase center of the satellite at the signal transmit time. $\mathrm{d} t_{u}$ and $\mathrm{d} t_{i}$ are the clock offsets of the receiver and satellite respectively. $I_{i}$ and $T_{i}$ refer to the ionosphere and troposphere delay. $e_{i}$ means the measurement noise and the un-modeled errors such as multi-path errors. $c$ is the speed of light in a vacuum.

We further assume that the satellite clock error in the pseudorange observation and the atmosphere delay have already been corrected, and only the receiver clock error is considered in the measurement model. The measurement model can then be expressed as [6]

$$
\mathbf{L}=\mathbf{A X}+\mathbf{e},
$$

where $\mathbf{L}$ is the measurement vector, which is the difference between the corrected pseudorange and the pseudorange calculated by the approximate value of the coordinates. $\mathbf{X}$ refers to the unknown parameters which include the three dimensional positions and the receiver clock error (the unit is in meters), $\mathbf{A}$ is the design matrix. If the weight matrix $\mathbf{P}$ of measurement vector $\mathbf{L}$ is considered, the least square solution of the unknown parameters will be

$$
\hat{\mathbf{X}}=\left(\mathbf{A}^{\mathrm{T}} \mathbf{P A}\right)^{-1} \mathbf{A}^{\mathrm{T}} \mathbf{P} \mathbf{L}=\mathbf{Q}_{\hat{\mathbf{X}}} \mathbf{A}^{\mathrm{T}} \mathbf{P} \mathbf{L}
$$

where $\mathbf{Q}_{\hat{\mathbf{x}}}=\left(\mathbf{A}^{\mathrm{T}} \mathbf{P A}\right)^{-1}$. The geometric dilution of precision is defined as GDOP

$$
\text { GDOP }=\sqrt{\operatorname{tr}\left(\mathbf{Q}_{\hat{\mathbf{x}}}\right)} .
$$

The horizontal dilution of precision is defined as (HDOP) $[5,11]$

$$
\mathrm{HDOP}=\sqrt{q_{\mathrm{nn}}+q_{\mathrm{ee}}} .
$$

The vertical dilution of precision is defined as (VDOP)

$$
\mathrm{VDOP}=\sqrt{q_{\mathrm{uu}}} .
$$

The time dilution of precision is defined as (TDOP)

$$
\mathrm{TDOP}=\sqrt{q_{\mathrm{tt}}} .
$$

To analyze the contribution of Compass to the PNT users, assume that the covariance of the unknown parameters $\hat{\mathbf{X}}_{\mathbf{0}}$ resolved from other satellite navigation systems is $\mathbf{Q}_{\hat{\mathbf{X}}_{0}}$. When considering the Compass signal, the measurement equation is changed to

$$
\left[\begin{array}{c}
\mathbf{L} \\
\mathbf{L}_{\mathrm{c}}
\end{array}\right]=\left[\begin{array}{c}
\mathbf{A} \\
\mathbf{A}_{\mathrm{c}}
\end{array}\right] \mathbf{X}+\left[\begin{array}{c}
\mathbf{e} \\
\mathbf{e}_{\mathrm{c}}
\end{array}\right],
$$

where $\mathbf{L}_{\mathrm{c}}$ and $\mathbf{P}_{\mathrm{c}}$ are the measurement vector and its 
weight matrix for Compass, and $\mathbf{A}_{\mathrm{c}}$ is the design matrix of Compass. Then the new covariance matrix of the unknown parameter vector $\hat{\mathbf{X}}$ after adding the Compass signal is

$$
\begin{aligned}
\mathbf{Q}_{\hat{\mathbf{x}}} & =\left(\left[\begin{array}{c}
\mathbf{A} \\
\mathbf{A}_{\mathrm{c}}
\end{array}\right]^{\mathrm{T}}\left[\begin{array}{cc}
\mathbf{P} & \mathbf{0} \\
\mathbf{0} & \mathbf{P}_{\mathrm{c}}
\end{array}\right]\left[\begin{array}{c}
\mathbf{A} \\
\mathbf{A}_{\mathrm{c}}
\end{array}\right]\right)^{-1}=\left(\mathbf{A}^{\mathrm{T}} \mathbf{P} \mathbf{A}+\mathbf{A}_{\mathrm{c}}^{\mathrm{T}} \mathbf{P}_{\mathrm{c}} \mathbf{A}_{\mathrm{c}}\right)^{-1} \\
& =\mathbf{Q}_{\hat{\mathbf{x}}_{0}}-\mathbf{Q}_{\hat{\mathbf{X}}_{0}} \mathbf{A}_{\mathrm{c}}^{\mathrm{T}}\left(\mathbf{Q}_{\mathrm{c}}+\mathbf{A}_{\mathrm{c}} \mathbf{Q}_{\hat{\mathbf{x}}_{0}} \mathbf{A}_{\mathrm{c}}^{\mathrm{T}}\right)^{-1} \mathbf{A}_{\mathrm{c}} \mathbf{Q}_{\hat{\mathbf{x}}_{0}},
\end{aligned}
$$

where $\mathbf{Q}_{\hat{\mathbf{x}}_{0}}=\left(\mathbf{A}^{\mathrm{T}} \mathbf{P A}\right)^{-1}, \quad \mathbf{Q}_{\mathrm{c}}=\mathbf{P}_{\mathrm{c}}^{-1}$ is the inverse matrix of the weight matrix of the Compass measurement. The improvement to the covariance of the PNT parameters is

$$
\mathbf{Q}_{\hat{\mathbf{x}}_{0}}-\mathbf{Q}_{\hat{\mathbf{x}}}=\mathbf{Q}_{\hat{\mathbf{x}}_{0}} \mathbf{A}_{\mathrm{c}}^{\mathrm{T}}\left(\mathbf{Q}_{\mathrm{c}}+\mathbf{A}_{\mathrm{c}} \mathbf{Q}_{\hat{\mathbf{x}}_{0}} \mathbf{A}_{\mathrm{c}}^{\mathrm{T}}\right)^{-1} \mathbf{A}_{\mathrm{c}} \mathbf{Q}_{\hat{\mathbf{x}}_{0}} \cdot
$$

The improvement to the DOP is

$$
\Delta \mathrm{DOP}=\sqrt{\operatorname{tr}\left(\mathbf{Q}_{\hat{\mathbf{X}}_{0}}\right)}-\sqrt{\operatorname{tr}\left(\mathbf{Q}_{\hat{\mathbf{X}}}\right)} .
$$

The percentage of the improvement to the DOP is

$$
\xi_{\text {DOP }}=\frac{\sqrt{\operatorname{tr}\left(\mathbf{Q}_{\hat{\mathbf{x}}_{0}}\right)}-\sqrt{\operatorname{tr}\left(\mathbf{Q}_{\hat{\mathbf{x}}}\right)}}{\sqrt{\operatorname{tr}\left(\mathbf{Q}_{\hat{\mathbf{x}}_{0}}\right)}} .
$$

The incompatibility of different satellite navigation systems should be considered in the multi-navigation-system environment. This refers mainly to the coordinate and time system errors between the different systems. The difference between the International Terrestrial Reference Frame (ITRF) and the coordinate reference frame of GPS, Galileo, and Compass (respectively, WGS-84, CTRF, CGCS2000) is only a few centimeters. Their difference can be ignored for navigation [1,12]. The coordinate system of GLONASS PZ-90 is a little different from ITRF. However, many organizations have already calculated the transform parameters. For navigation applications whose precision is at the meter level, we should consider these parameters, but have no need to add new unknown parameters in the function model. Therefore, the coordinate system difference has no influence on the calculation of the DOP.

There are generally two ways to deal with the differences in the time systems [1,13]: (1) Broadcasting the time difference between different systems to users in the broadcast ephemeris [14]. (2) Adding an unknown time system error parameter to the estimate. For the following calculations and analysis, these two ways are considered, first to calculate the value of the DOP, and then to analyze the contribution of Compass.

\section{Computation and analysis}

The simulation time was from 0.00 hours, March 28 to 0.00 hours, March 29, 2010. The sampling interval was 300 s. For GPS and GLONASS we took the broadcast ephemeris of that day to calculate the positions of the satellites. While for Compass and Galileo, the position parameters were calculated using Kelperian orbit parameters listed in Table 1. During the simulation period, 30 GPS satellites, 21 GLONASS satellites, 27 Galileo satellite, and 35 Compass satellites were employed.

The 5 GEO satellites of Compass were located at $58.75^{\circ}$, $80^{\circ}, 110.5^{\circ}, 140^{\circ}$ and $160^{\circ} \mathrm{E}$. The inclination of the 3 IGSO satellites were $55^{\circ}$, and the longitude of their crossing node is $118^{\circ} \mathrm{E}$.

Eight computation schemes were performed.

Scheme 1: GPS (G)

Scheme 2: GPS+Compass $(\mathrm{G}+\mathrm{C})$

Scheme 3: GPS+GLONASS (G+R)

Scheme 4: GPS+GLONASS+Compass $(\mathrm{G}+\mathrm{R}+\mathrm{C})$

Scheme 5: GPS+Galileo $(\mathrm{G}+\mathrm{E})$

Scheme 6: GPS+Galileo +Compass $(\mathrm{G}+\mathrm{E}+\mathrm{C})$

Scheme 7: GPS+GLONASS+Galileo $(\mathrm{G}+\mathrm{R}+\mathrm{E})$

Scheme 8: GPS+GLONASS+Galileo+Compass $(\mathrm{G}+\mathrm{R}+\mathrm{E}$ $+\mathrm{C})$

( G, R, E, and C are the abbreviation of GPS, GLONASS, Galileo, and Compass).

The coverage of the calculation area was global, that is to say: from $180^{\circ} \mathrm{E}$ to $180^{\circ} \mathrm{W}$, from $90^{\circ} \mathrm{N}$ to $90^{\circ} \mathrm{S}$. The resolution was $5^{\circ}$ by $2.5^{\circ}$, the altitude was set to $25 \mathrm{~m}$. The visible satellites of different navigation systems at different mask angles $\left(10^{\circ}, 20^{\circ}, 30^{\circ}\right.$ and $40^{\circ}$ respectively) was calculated, as were the DOP values of the different schemes and the improvement percentages at a mask angle of $10^{\circ}$. The details of the results are shown in Tables 2-7 and Figures 1-10.

Table 1 Orbit parameters for the Compass and Galileo satellites ${ }^{\text {a) }}$

\begin{tabular}{ccc}
\hline & Compass & Galileo \\
\hline$a(\mathrm{~km})$ & 27878.1 & 29601.297 \\
$i\left(^{\circ}\right)$ & 55 & 0 \\
$e$ & 0 & $0,120,240$ \\
$\omega\left(^{\circ}\right)$ & The mean anomaly of the first satellite in every orbit at the start- & 0 \\
$\Omega\left(^{\circ}\right)$ & ing epoch is $0^{\circ}, 15^{\circ}, 30^{\circ}$, the others increase to $45^{\circ}$ successively. & The mean anomaly of the first satellite in every orbit at the start- \\
& In addition, the mean anomalies of the backup satellite in 3 orbits & ing epoch is $0^{\circ}, 15^{\circ}, 30^{\circ}$, the others increase to $40^{\circ}$ successively. \\
\hline
\end{tabular}

a) $a$ means the major semi-axis, $i$ refers to the inclination angle, $e$ is the orbit eccentricity, $\omega$ is the argument of the perigee, $\Omega$ denotes an ascending node, $M_{0}$ is the mean anomaly. 
Table 2 Number of visible satellites at different mask angles

\begin{tabular}{|c|c|c|c|c|c|c|c|c|}
\hline & \multicolumn{2}{|c|}{$10^{\circ}$} & \multicolumn{2}{|c|}{$20^{\circ}$} & \multicolumn{2}{|c|}{$30^{\circ}$} & \multicolumn{2}{|c|}{$40^{\circ}$} \\
\hline & $\min -\max$ & mean & $\min -\max$ & mean & $\min -\max$ & mean & $\min -\max$ & mean \\
\hline G & $6-9$ & 7.3 & $4-7$ & 5.2 & $2-5$ & 3.3 & $1-3$ & 1.7 \\
\hline $\mathrm{G}+\mathrm{C}$ & $12-25$ & 17.1 & $9-20$ & 12.6 & $5-15$ & 8.8 & $3-11$ & 5.1 \\
\hline $\mathrm{G}+\mathrm{R}$ & $9-15$ & 12.6 & $6-12$ & 9.2 & $4-9$ & 6.2 & $1-5$ & 3.5 \\
\hline $\mathrm{G}+\mathrm{R}+\mathrm{C}$ & $16-30$ & 22.6 & $11-24$ & 16.7 & $7-17$ & 11.7 & $4-12$ & 7.0 \\
\hline $\mathrm{G}+\mathrm{E}$ & $12-18$ & 15.2 & $9-14$ & 11.4 & $6-10$ & 7.9 & $3-6$ & 4.6 \\
\hline $\mathrm{G}+\mathrm{E}+\mathrm{C}$ & $20-34$ & 25.6 & $15-26$ & 19.0 & $10-19$ & 13.3 & $5-14$ & 8.2 \\
\hline $\mathrm{G}+\mathrm{R}+\mathrm{E}$ & $16-24$ & 20.7 & $12-19$ & 15.5 & $7-14$ & 10.9 & $3-8$ & 6.5 \\
\hline $\mathrm{G}+\mathrm{R}+\mathrm{E}+\mathrm{C}$ & 24-39 & 31.1 & $17-30$ & 23.2 & $11-22$ & 16.3 & $6-16$ & 10.1 \\
\hline
\end{tabular}

Table 3 DOP values of different schemes (mask angle is $10^{\circ}$, considering the time system difference)

\begin{tabular}{|c|c|c|c|c|c|c|c|c|}
\hline & \multicolumn{2}{|c|}{ GDOP } & \multicolumn{2}{|c|}{ PDOP } & \multicolumn{2}{|c|}{ HDOP } & \multicolumn{2}{|c|}{ VDOP } \\
\hline & $\min -\max$ & mean & $\min -\max$ & mean & $\min -\max$ & mean & $\min -\max$ & mean \\
\hline $\mathrm{G}$ & $2.33-4.59$ & 3.43 & $2.06-3.90$ & 2.96 & $0.90-2.17$ & 1.33 & $1.77-3.57$ & 2.67 \\
\hline $\mathrm{G}+\mathrm{C}$ & $1.27-2.36$ & 1.84 & $1.04-2.02$ & 1.52 & $0.54-0.97$ & 0.72 & $0.90-1.90$ & 1.35 \\
\hline $\mathrm{G}+\mathrm{R}$ & $1.85-2.95$ & 2.25 & $1.55-2.43$ & 1.87 & $0.71-1.16$ & 0.87 & $1.34-2.13$ & 1.67 \\
\hline $\mathrm{G}+\mathrm{R}+\mathrm{C}$ & $1.30-2.03$ & 1.67 & $0.94-1.59$ & 1.26 & $0.49-0.78$ & 0.60 & $0.81-1.49$ & 1.12 \\
\hline $\mathrm{G}+\mathrm{E}$ & $1.62-2.47$ & 1.99 & $1.34-2.03$ & 1.65 & $0.60-0.94$ & 0.76 & $1.18-1.84$ & 1.48 \\
\hline $\mathrm{G}+\mathrm{E}+\mathrm{C}$ & $1.22-1.91$ & 1.57 & $0.90-1.48$ & 1.18 & $0.45-0.68$ & 0.55 & $0.78-1.39$ & 1.05 \\
\hline $\mathrm{G}+\mathrm{R}+\mathrm{E}$ & $1.51-2.05$ & 1.75 & $1.16-1.58$ & 1.34 & $0.52-0.81$ & 0.64 & $0.99-1.39$ & 1.19 \\
\hline $\mathrm{G}+\mathrm{R}+\mathrm{E}+\mathrm{C}$ & $1.30-1.79$ & 1.54 & $0.84-1.26$ & 1.05 & $0.42-0.60$ & 0.49 & $0.72-1.17$ & 0.93 \\
\hline
\end{tabular}

Table 4 DOP values of different schemes (mask angle is $10^{\circ}$, without considering the time system difference)

\begin{tabular}{|c|c|c|c|c|c|c|c|c|}
\hline & \multicolumn{2}{|c|}{ GDOP } & \multicolumn{2}{|c|}{ PDOP } & \multicolumn{2}{|c|}{ HDOP } & \multicolumn{2}{|c|}{ VDOP } \\
\hline & $\min -\max$ & mean & $\min -\max$ & mean & $\min -\max$ & mean & $\min -\max$ & mean \\
\hline G & $2.33-5.59$ & 3.43 & $2.06-3.90$ & 2.96 & $0.90-2.17$ & 1.33 & $1.77-3.57$ & 2.67 \\
\hline $\mathrm{G}+\mathrm{C}$ & $1.16-2.29$ & 1.71 & $1.02-2.02$ & 1.49 & $0.53-0.94$ & 0.70 & $0.87-1.89$ & 1.33 \\
\hline $\mathrm{G}+\mathrm{R}$ & $1.69-2.57$ & 2.07 & $1.50-2.15$ & 1.80 & $0.69-1.13$ & 0.85 & $1.29-1.94$ & 1.60 \\
\hline $\mathrm{G}+\mathrm{R}+\mathrm{C}$ & $1.04-1.70$ & 1.39 & $0.92-1.48$ & 1.22 & $0.48-0.76$ & 0.59 & $0.79-1.39$ & 1.07 \\
\hline $\mathrm{G}+\mathrm{E}$ & $1.50-2.32$ & 1.85 & $1.33-1.98$ & 1.61 & $0.60-0.93$ & 0.75 & $1.16-1.83$ & 1.44 \\
\hline $\mathrm{G}+\mathrm{E}+\mathrm{C}$ & $0.98-1.64$ & 1.31 & $0.88-1.45$ & 1.15 & $0.45-0.66$ & 0.54 & $0.75-1.37$ & 1.02 \\
\hline $\mathrm{G}+\mathrm{R}+\mathrm{E}$ & $1.27-1.71$ & 1.48 & $1.13-1.46$ & 1.29 & $0.52-0.78$ & 0.62 & $0.97-1.34$ & 1.14 \\
\hline $\mathrm{G}+\mathrm{R}+\mathrm{E}+\mathrm{C}$ & $0.91-1.37$ & 1.15 & $0.81-1.21$ & 1.01 & $0.42-0.58$ & 0.48 & $0.70-1.11$ & 0.89 \\
\hline
\end{tabular}

Table 5 Contribution of Compass to the DOP (mask angle is $10^{\circ}$, considering the time system difference) (\%)

\begin{tabular}{|c|c|c|c|c|c|c|c|c|}
\hline & \multicolumn{2}{|c|}{ GDOP } & \multicolumn{2}{|c|}{ PDOP } & \multicolumn{2}{|c|}{ HDOP } & \multicolumn{2}{|c|}{ VDOP } \\
\hline & $\min -\max$ & mean & $\min -\max$ & mean & $\min -\max$ & mean & $\min -\max$ & mean \\
\hline G & $28.6-66.5$ & 46.1 & $32.4-68.2$ & 48.5 & $27.1-69.2$ & 45.3 & $31.5-69.1$ & 49.1 \\
\hline $\mathrm{G}+\mathrm{R}$ & $14.3-45.4$ & 25.6 & $21.0-51.4$ & 32.4 & $20.7-44.9$ & 30.7 & $19.9-52.6$ & 33.0 \\
\hline $\mathrm{G}+\mathrm{E}$ & $11.0-36.8$ & 21.1 & $17.5-46.0$ & 28.3 & $17.5-40.7$ & 27.6 & $17.5-47.7$ & 28.7 \\
\hline $\mathrm{G}+\mathrm{R}+\mathrm{E}$ & $3.1-25.4$ & 11.6 & $13.2-35.7$ & 22.0 & $14.3-34.3$ & 22.3 & $12.2-38.1$ & 22.2 \\
\hline
\end{tabular}


Table 6 Contribution of Compass to the DOP (mask angle is $10^{\circ}$, only considering the Compass time system difference) (\%)

\begin{tabular}{|c|c|c|c|c|c|c|c|c|}
\hline & \multicolumn{2}{|c|}{ GDOP } & \multicolumn{2}{|c|}{ PDOP } & \multicolumn{2}{|c|}{ HDOP } & \multicolumn{2}{|c|}{ VDOP } \\
\hline & $\min -\max$ & mean & $\min -\max$ & mean & $\min -\max$ & mean & $\min -\max$ & mean \\
\hline $\mathrm{G}$ & $28.6-66.5$ & 46.1 & $32.4-68.2$ & 48.5 & $27.1-69.2$ & 45.3 & $31.5-69.1$ & 49.1 \\
\hline $\mathrm{G}+\mathrm{E}$ & $12.8-41.7$ & 23.8 & $18.0-45.7$ & 27.7 & $17.7-41.1$ & 27.3 & $17.1-46.4$ & 28.0 \\
\hline $\mathrm{G}+\mathrm{R}+\mathrm{E}$ & $6.5-32.5$ & 16.2 & $10.4-34.6$ & 21.0 & $14.3-33.8$ & 21.7 & $9.8-36.0$ & 21.2 \\
\hline
\end{tabular}

Table 7 Contribution of Compass to the DOP (mask angle is $10^{\circ}$, without considering the time system difference) (\%)

\begin{tabular}{|c|c|c|c|c|c|c|c|c|}
\hline & \multicolumn{2}{|c|}{ GDOP } & \multicolumn{2}{|c|}{ PDOP } & \multicolumn{2}{|c|}{ HDOP } & \multicolumn{2}{|c|}{ VDOP } \\
\hline & $\min -\max$ & mean & $\min -\max$ & mean & $\min -\max$ & mean & $\min -\max$ & mean \\
\hline G & $32.8-70.3$ & 50.1 & $32.9-68.7$ & 49.5 & $27.1-69.7$ & 46.3 & $32.0-69.6$ & 50.1 \\
\hline $\mathrm{G}+\mathrm{R}$ & $18.0-48.7$ & 32.7 & $18.2-49.0$ & 32.3 & $20.9-46.9$ & 31.0 & $18.0-52.5$ & 32.8 \\
\hline $\mathrm{G}+\mathrm{E}$ & $18.1-48.3$ & 29.5 & $18.2-47.3$ & 29.0 & $18.0-42.2$ & 28.1 & $17.1-49.4$ & 29.5 \\
\hline $\mathrm{G}+\mathrm{R}+\mathrm{E}$ & $11.1-37.7$ & 22.6 & $10.4-36.4$ & 22.2 & $14.3-35.6$ & 22.5 & $9.76-36.8$ & 22.5 \\
\hline
\end{tabular}

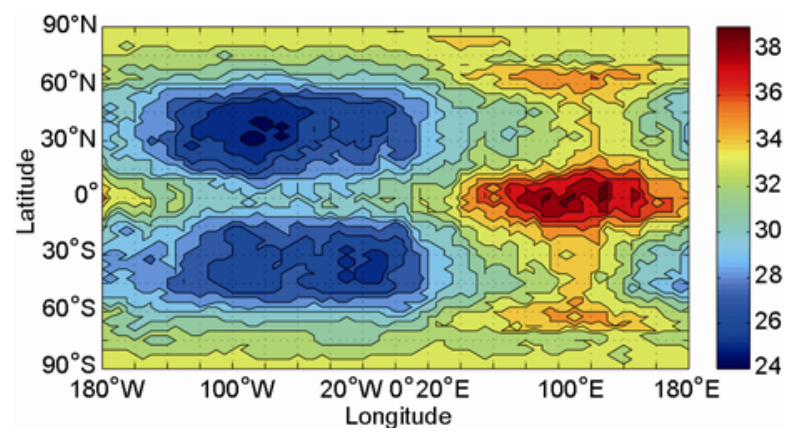

Figure 1 No. of visible satellites for Scheme 8 (maslc angle $\left.10^{\circ}\right)$.

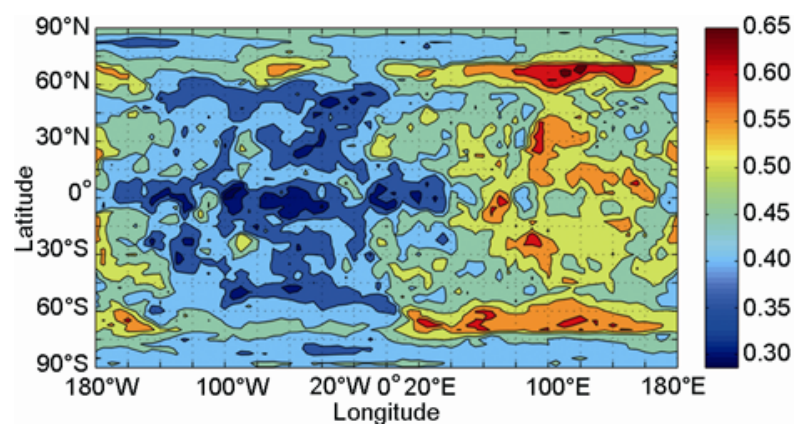

Figure 3 GDOP improvement (Scheme 2 compared to Scheme 1).

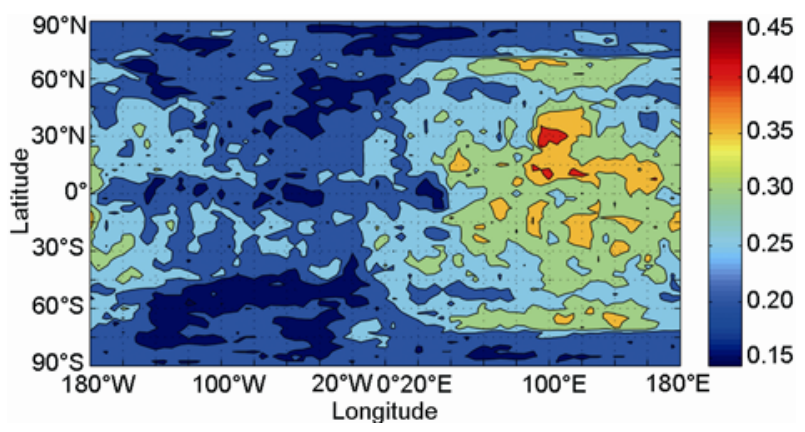

Figure 5 GDOP improvement (Scheme 4 compared to Scheme 3).

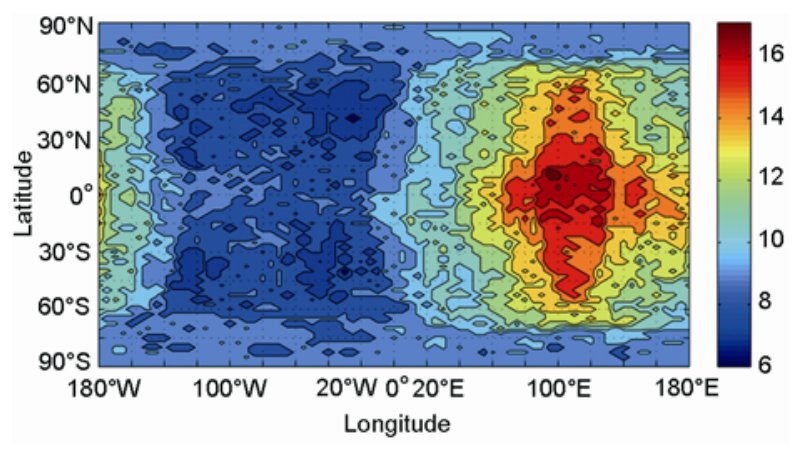

Figure 2 Increase in No. of visible satellites (Scheme 8 compared to Scheme 7)

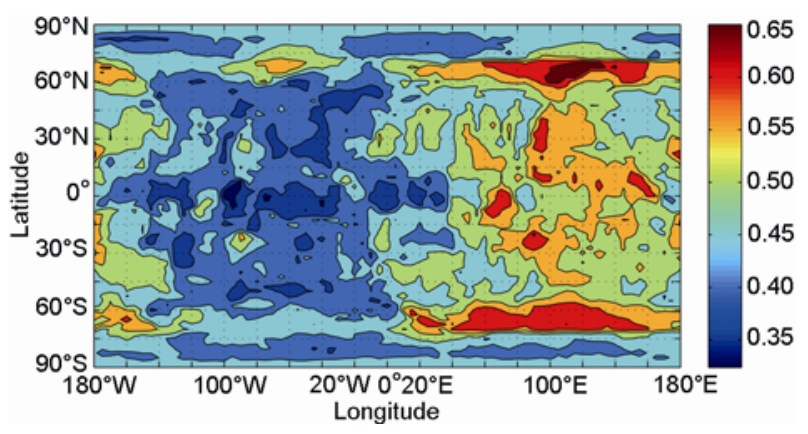

Figure 4 PDOP improvement (Scheme 2 compared to Scheme 1).

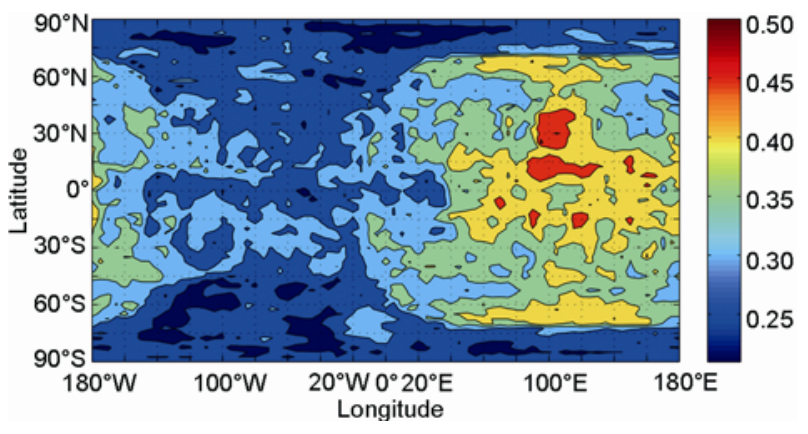

Figure 6 PDOP improvement (Scheme 4 compared to Scheme 3). 


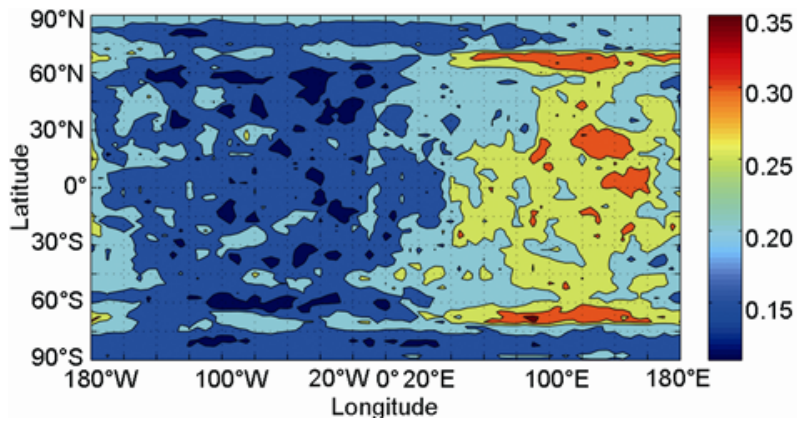

Figure 7 GDOP improvement (Scheme 6 compared to Scheme 5)

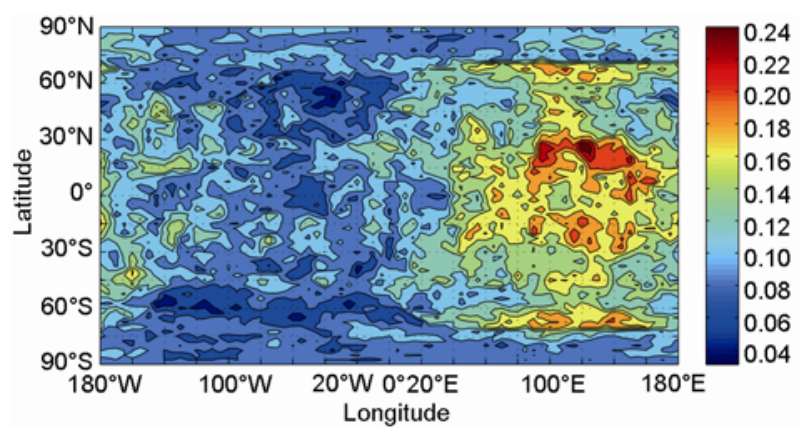

Figure 9 GDOP improvement (Scheme 8 compared to Scheme 7).

From these results, the following conclusions can be drawn:

(1) Comparing Schemes 1 and 2 in Table 2, we find that when the Compass co-worked with GPS, the average number of visible satellites increased from 7.3 to 17.1 , an increase of about 134\%; for Schemes 3 and 4, and Schemes 5 and 6, when Compass was combined with GPS+GLONASS and GPS+Galileo respectively, the number of visible satellites increased by about $79 \%$ and $68 \%$. Even when GPS, Galileo and GLONASS were all operated, the participation of Compass was still useful. The number of visible satellites increased from 20.7 to 31.1 , that is, about $50 \%$. The increase in visible satellites will ameliorate the geometry of the satellite, and enhance the continuity of the PNT service.

(2) The contribution of Compass to the GDOP of different systems increased as the compatibility of different system increased. This can easily be seen in Tables 5-7. If all the navigation systems were totally compatible (no system error), if Compass was added to GPS, the global GDOP would improve by about 50\%; and if Compass worked together with GPS and Galileo, the improvement would be 29.5\%. Even when GPS, Galileo, and GLONASS are all available, Compass can still contribute to the improvement of GDOP $(22.6 \%)$. The enhancement of the compatibility of different systems will lead to the improvement of GDOP, and further improve the accuracy of PNT.

(3) It can be seen from Tables 5, 6 and 7: that whether the system time difference was considered or not, when Compass was add to GPS, the improvement to the position

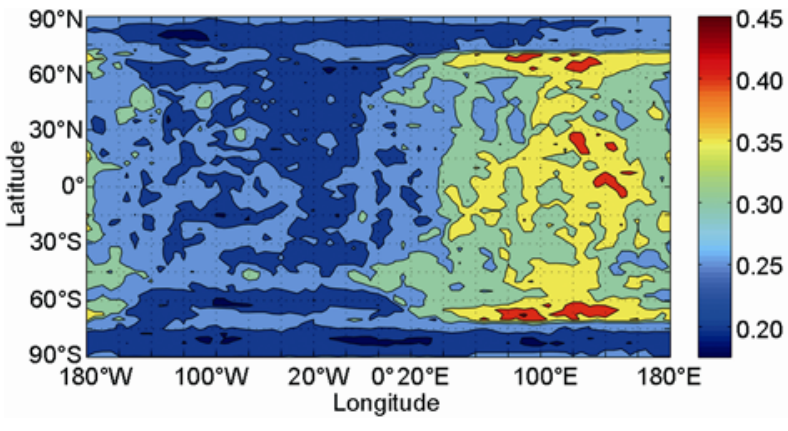

Figure 8 PDOP improvement (Scheme 6 compared to Scheme 5)

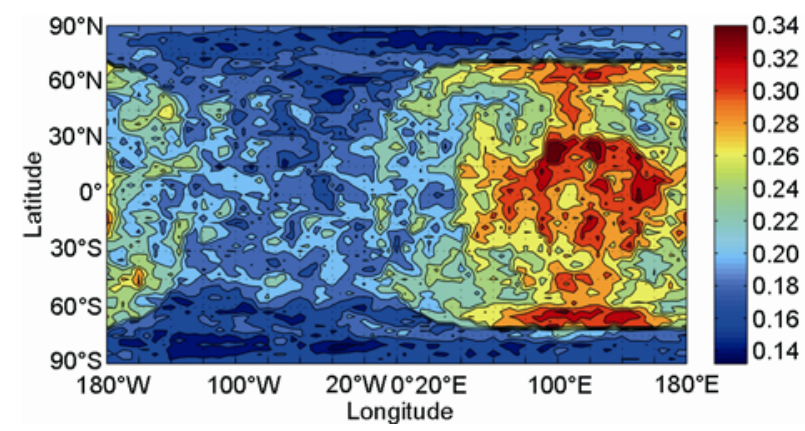

Figure 10 PDOP improvement (Scheme 8 compared to Scheme 7).

dilution of precision (PDOP) was about 49\%; when added to GPS and GLONASS, the PDOO improved by about $32 \%$; when added to GPS and Galileo, the improvement was $28 \%$. Even when GPS, GLONASS and Galileo were all in use, Compass could still contribute to the enhancement of the PDOP, and the improvement was about $22 \%$. The improvement in PDOP will enhance the precision of the navigation service, and thus ameliorate the availability of the service.

(4) For sheltered areas such as a city street surrounded by high buildings, only a few satellites from a single system were available. When the mask angle was $40^{\circ}$, there were less than 4 visible satellites from a single system, and this is inconvenient for users. When all four systems are employed, the average number of visible satellites is 10.1 . Therefore, the availability of the navigation service will be noticeably enhanced when several system are operated together.

Finally, it is pointed out that too many compatible compensating parameters are needed for GNSS data fusion when the compatibility of different navigation systems is poor. For this situation, the GDOP will evidently not be improved when more constellations are added. Besides, the stochastic model and weighting of measurements for different types of navigation satellites are different, so the contribution of different satellites cannot be evaluated using DOP derived from equal weighting. In practice, we can determine the weighting of different satellites by estimating the variance components, and then calculating the DOP values. This problem will be discussed in other papers. 
This work was supported by the National Natural Science Foundation of China (41020144004 and 40841021) and the National High-Tech Research \& Development Program of China (2007AA12Z331).

1 Hofmann-Wellenhof B, Lichtenegger H, Wasle E. GNSS-Global Navigation Satellite Systems: GPS, GLONASS, Galileo \& More (in Chinese). Beijing: Surveying and Mapping Press, 2009

2 Chen Z G, Shuai P, Qu G J. Analysis of the technical character and develop tendency of modern satellite navigation system (in Chinese). Sci China Ser E Tech Sci, 2009, 39: 686-695

3 Chen J Y. On progress in technology and modernization of GPS (in Chinese). J Geod Geodyn, 2010, 30:1-4

4 Yang Y X. Progress, contribution and challenges of Compass/Beidu satellite navigation system (in Chinese). Acta Geod Cartogr Sci, 2010, 39: $1-6$

5 Milbert D. Improving dilution of precision, a companion measure of systematic effects. GPS World, 2009, 20: 38-47

6 Langley R B. Dilution of precision. GPS World, 1999, 10: 52-59

7 Zhao C M, Ou J K, Yuan Y B. Positioning accuracy and reliability of
Galileo, integrated GPS-Galileo system based on single positioning model. Chinese Sci Bull, 2005, 50: 1252-1260

8 Tsai M L. The performance analysis for future GNSS in Taiwan region. Dissertation for the Master's Degree. Taiwan: Cheng Kung University, 2008

9 Huang Y S, Tsai M L. The impact of Compass/Beidou-2 on future GNSS: A perspective from Asia. In: ION GNSS 21st. International Technical Meeting of the Satellite Division, 16-19, September 2008, Savannah, GA, 2227-2238

10 Zhuang X Y, Zhao X D, Tan S S, et al. Simulation and analysis of interference between Compass and GPS in L1 band (in Chinese). J Geom Sci Tech, 2009, 26: 216-219

11 Milbert D. Dilution of precision. J Inst Navi, 2008, 55: 67-81

12 Yang Y X. Chinese geodetic coordinate system 2000. Chinese Sci Bull, 2009, 54: 2714-2721

13 Kaplan D, Hegarty C J. Understanding GPS Principles and Applications (in Chinese). 2nd ed. Beijing: Publishing House of Electronics Industry, 2007

14 Hahn J, Powers E. GPS and Galileo timing interoperability. In: Proc. of GNSS 2004, Rotterdam, the Netherlands, May 2004

Open Access This article is distributed under the terms of the Creative Commons Attribution License which permits any use, distribution, and reproduction in any medium, provided the original author(s) and source are credited. 